\title{
O provedor de justiça europeu e a democratização das instituições comunitárias
}

\author{
The European ombudsman and the democratization \\ of the $E U$ institutions
}

JANAÍNA RIGO SANTIN*

Rev. Bras. Polít. Int. 55 (2): 152-169 [2012]

Considerações iniciais: a ideia de cidadania europeia

Um dos objetivos da União Europeia encontra-se no artigo B do Tratado da União Europeia, que reforça a "defesa dos direitos e dos interesses nacionais dos seus Estados-Membros, mediante a instituição de uma cidadania da União; [...]". Logo, denota-se a preocupação fundamental em concretizar um nível de cidadania capaz de abraçar toda a União Europeia, indo além das fronteiras dos Estados-Membros que a compõe.

A teoria de Ingolf Pernice $(2012,707)$ do constitucionalismo multinível parte de uma ideia questionável, da transferência de legitimidade democrática dos cidadãos de cada um dos Estados-Membros para a União Europeia e suas instituiçôes. Por certo, as decisões nos órgãos comunitários estão umbilicalmente ligadas às estruturas estatais, não sendo possível essa transferência de legitimidade. Trata-se de uma perda de qualidade democrática, em verdade. Porém, essa teoria tem o mérito de apontar a diversidade dos espaços institucionais da Europa e a desnecessidade de uma constituição comum, visto que outros caminhos chegam também a uma organização constitucional.

Os setores eurocéticos, nas palavras de Habermas (2012, 6), afirmam que ainda não está presente uma identidade, um povo europeu. E nessa senda o conceito de povo também é bastante problemático. Entretanto, povo não é um conceito coerente para a ideia de sociedade multicultural e pluralista como a europeia. Nas palavras de Dieter Grimm (2006), a língua também é um elemento importante para se construir uma cidadania europeia comum, não havendo essa característica

\footnotetext{
* Possui graduação em Direito pela Universidade de Passo Fundo (1996), mestrado em Direito pela Universidade Federal de Santa Catarina (2000), Doutorado em Direito pela Universidade Federal do Paraná; (2004) e Pós-Doutorado em Direito Administrativo pela Universidade de Lisboa (Portugal). Professora-adjunta III da Universidade de Passo Fundo. Faz parte do corpo docente permanente do Mestrado em História pela Universidade de Passo Fundo. Advogada e professora da Graduação e Pós-Graduação lato sensu da Faculdade de Direito da Universidade de Passo Fundo (janainars@upf.br).
} 
na Europa. E os setores eurocéticos exploram isso entendendo que a falta de uma língua comum dificultaria um debate público europeu, capaz de criar um espaço democrático comum em que necessidades e interesses sociais pudessem ser debatidos por amplos setores da sociedade.

Entretanto, para Habermas (2012), não há a necessidade de uma língua oficial para constituir cidadãos comuns. $\mathrm{O}$ autor defende os seguintes pré-requisitos funcionais de um projeto de União Europeia, constituída democraticamente: a) a necessidade de um espaço público conjunto, construído a partir de elementos de identidade capazes de construir uma identidade comum, "una red que dé a los ciudadanos de todos los Estados miembros la misma oportunidad de tomar parte en un amplio proceso de comunicación política concreta"; b) a emergência de uma sociedade civil europeia; e, por fim, c) a formação de uma cultura política que possa ser compartilhada por todos os cidadãos europeus. Tais elementos seriam diferentes daqueles da modernidade, tradicionais, como a língua e o povo.

Concorda-se com o argumento habermasiano. Trata-se, na opinião de Baldomero Oliver León (2012), da "dimensão multilateral da cidadania europeia", a qual gera uma relação direta dos cidadãos com a Uniāo Europeia e as instituições comunitárias, da mesma forma que impóe aos ordenamentos dos Estados-Membros reconhecerem essa cidadania. Afinal, o cidadão deve ser o sujeito e fim mesmo da existência da União.

Peter Haberle (2012) alerta para uma situação de deficit democrático bastante presente na Europa: as convenções e tratados não são representativos da população, já que somente Estados nacionais continuam sendo os "senhores dos Tratados". E aqui reside sua grande crítica: é preciso avançar do que se tem hoje na União Europeia, criando-se mecanismos de inserção e participação do povo como, por exemplo, referendos de dimensão europeia. E, da mesma forma, o que se defende no presente artigo é a necessidade de criar instituições capazes de conectar órgãos comunitários e a cidadania europeia, como o Provedor de Justiça Europeu, assunto a ser abordado neste artigo.

Em verdade, não há uma fórmula histórica unificada para o desenvolvimento da forma política da União Europeia. O processo de constitucionalização e o aprimoramento das instituições democráticas em âmbito europeu devem seguir seu rumo, até se chegar a uma cidadania baseada em uma constituição europeia comum. Por certo que o alcance desses objetivos depende de vários fatores, e não apenas de uma vontade política.

\section{Constitucionalismo e cidadania europeia: haverá um espaço público europeu?}

A formação dos Estados modernos do século 19 permitiu a construção de identidades nacionais, não tanto a partir da vontade dos indivíduos, mas de uma ação do poder político, dirigida a esse sentido, voltada à formação de uma Nação. 
Porém, na União Europeia, a construção de uma identidade comum não pode ser dada da mesma forma, pois não pode suplantar as identidades nacionais, substituindo-as. A construção de uma identidade europeia deve ser dada a partir da ideia de cidadania e de pertencimento, de um estatuto jurídico comum. (Callejón 2010, 212-219).

A partir das conclusões de Habermas, entende-se que é preciso avançar, no sentido de criação de um espaço público europeu, uma cidadania europeia, uma unidade entre os cidadãos integrantes desse grande bloco. Nas palavras do autor, "la opacidad en los procesos de toma de decisión a escala europea y la ausencia de posibilidad de participación en ellos produce desconfianza entre los ciudadanos" $(2012$, 6). É preciso constituir-se um vínculo de solidariedade entre as pessoas, uma identidade comum capaz de ser projetada em suas instituições, a fim de que se desenvolva um sentido de pertencimento e participação política pelos cidadãos ao nível de instituiçôes europeias.

De nada adianta falar de uma constituição europeia quando não se constrói conjuntamente um sistema democrático, um espaço em que haja um debate público sobre problemas comuns, em que sejam mediados os conflitos. A constituição não é fruto apenas de uma vontade política, nem pode, em Estados Democráticos de Direito, ser imposta. São necessárias condiçōes políticas, culturais, jurídicas e sociais para que se permita falar de um direito constitucional comum. Talvez ainda não seja a hora de haver uma constituição europeia, visto que tais condições ainda não existem, bem como inexiste um espaço público de discussão e inter-relação pessoal entre os cidadãos europeus e seus representantes. Porém, é preciso caminhar para a criação de um espaço público de decisões fundamentais na Europa, combatendo a fragmentação da cidadania europeia nos espaços públicos estatais. (Callejón 2010, 216-217).

O problema da Europa hoje são as competências que deve assumir para tomar as decisōes fundamentais capazes de fazer frente à globalização. E para isso precisa adotar mecanismos ágeis e rápidos de decisão, com a transferência maior de competências para as instituições europeias, a qual necessariamente deve vir unida a uma maior democratização dessas instituiçōes, visto que o deficit democrático da Europa é algo bastante presente. É uma questão não só de funcionalidade e operacionalidade como também de democracia.

E nesse sentido, a instituição do Provedor de Justiça Europeu é um passo importante no caminho de uma maior participação e controle dos cidadãos europeus perante os seus representantes nas instituiçôes comunitárias.

\section{O Provedor de Justiça: uma importante instituição na construção dos direitos de cidadania europeus}

O Tratado de Lisboa, ao atribuir valor jurídico à Carta de Direitos Fundamentais da União Europeia, positiva um importante instrumento nas mãos dos 
cidadãos europeus para controle e accountability de seus governantes: o direito a uma boa administração.

Assim dispóe o artigo 41 da Carta (2012):

1. Todas as pessoas têm direito a que seus assuntos sejam tratados pelas instituições e órgãos da União de forma imparcial, equitativa e num prazo razoável.

2. Este direito compreende, nomeadamente:

- o direito de qualquer pessoa a ser ouvida antes de ser tomada qualquer medida individual que a afecte desfavoravelmente,

- o direito de qualquer pessoa a ter acesso aos processos que se lhe refiram, no respeito dos legítimos interesses da confidencialidade e do segredo profissional e comercial,

- a obrigação, por parte da administração, de fundamentar as suas decisões.

3. Todas as pessoas têm o direito à reparação, por parte das instituiçôes ou pelos seus agentes no exercício das respectivas funções, de acordo com os princípios gerais comuns às legislaçôes dos Estados-Membros.

4. Todas as pessoas têm a possibilidade de se dirigir às instituições da União numa das línguas oficiais dos Tratados, devendo obter uma resposta na mesma língua.

Entretanto, não há qualquer codificação internacional para o termo "boa administração", cabendo à doutrina de direito nacional e comunitário esclarecer o seu alcance e sentido. Para Pierre-Yves Monette, antigo Provedor Federal da Bélgica, consiste em "organizar serviços públicos eficazes, acessíveis e transparentes" (Monette 2008, 208-225). Alguns países e organizações internacionais procuram elencar alguns princípios segundo os quais entendem que as suas administraçóes devam funcionar. Um exemplo a ser observado é o constante no site da Comissão Europeia, o qual elenca alguns princípios gerais de boa administração nas suas relações com o público. São eles: legalidade, não discriminação e igualdade de tratamento, proporcionalidade e coerência. (Princípios Gerais da Boa Administração 2012). Porém, grande parte delas não chega a ponto de os tornarem oponíveis aos utilizadores de seus serviços. $\mathrm{O}$ presente artigo pretenderá fazer uma análise mais aprofundada do direito fundamental a uma boa administração a partir de noções doutrinárias e, em especial, com o aprofundamento dos princípios de direito público relacionados ao dever de bem administrar.

\section{Direito Fundamental a uma Boa Administração}

No âmbito do direito administrativo, a noção jurídica de boa administração surge, teoricamente, a partir das liçôes do jurista francês Maurice Hauriou, relacionado diretamente ao princípio da moralidade administrativa. Para Hauriou, além da obrigatoriedade de o gestor atuar conforme o que está prescrito em lei, ele 
está vinculado a um conjunto de regras de conduta pertencentes à disciplina interna da Administração Pública que devem ser seguidas. Essas regras não precisam estar minuciosamente descritas em lei, mas são exigíveis pela obrigatoriedade de uma conduta ética, já que advêm do princípio da moralidade administrativa (1938, 232 e ss.).

Dessa forma, ao se positivar o direito a uma boa administração na Carta de Direitos Fundamentais da União Europeia, passa a se exigir um conjunto de deveres de boa conduta às instituiçôes e aos órgãos europeus, deveres estes decorrentes do princípio da moralidade, os quais não estão, necessariamente, implícitos. Entretanto, apesar da sua importância na configuração do termo, entende-se que o direito a uma boa administração vai além da exigência da moralidade administrativa.

Nas sociedades atuais, a exigência ético-normativa passa a ser consolidada, em especial quando se verifica a mudança do paradigma da administração burocrática ao modelo gerencial, contexto no qual são aumentados "os níveis de responsabilidade pessoal dos agentes públicos, suas liberdades, espaços discricionários e balizamentos éticos ligados a vetores de eficiência e boa administração" (Osório 2007, 43). Logo, já não basta atuar conforme a lei ou a ética; é preciso também ser eficiente, prestar contas de sua atuação e assumir responsabilidade por seus atos.

Nas palavras de Eduardo García de Enterría, a boa administração está ligada à relação de confiança que deve existir entre governantes e governados, uma exigência para estados democráticos. Essa confiança pode ser obtida mediante a obrigação dos administradores terem de prestar contas a seus administrados $(2000,108-109)$. Trata-se de uma definição mais próxima da noção anglo-saxônica de accountability.

Por sua vez, o termo "boa administração", nas palavras de Pierre-Yves Monette, está ligado ao termo "boa governação", mais abrangente e aplicado desde os anos 1980 pelo Banco Mundial, com vistas a orientar a gestão pública dos países devedores. Trata-se de um sentido bastante economicista ao termo, o qual vincula à boa governação os seguintes princípios: transparência, participação, precaução, segurança, analogia, eficiência, responsabilidade, imputabilidade, integralidade, moralidade, rigor e sustentabilidade financeira. Por fim, o autor aponta a necessária governação democrática, expressão do lugar central que o homem integra na boa governação. (Monette 2008, 208-225).

Em verdade, as opinióes doutrinárias acima trazem muitos referenciais com vistas a definir o sentido e alcance do termo "boa administração". Porém, advêm de um período anterior à positivação pela Carta de Direitos Fundamentais da União Europeia, na qual o direito a boa administração passou a ter um caráter de direito fundamental. Dessa forma, entende-se que é preciso partir da análise detalhada do artigo e seus incisos, na tentativa de dimensionar o alcance do artigo 41 .

$\mathrm{O}$ artigo $41 \$ 1$ fala do direito a uma Administração imparcial e equitativa. Trata-se de preceito inserido em grande parte das Constituições europeias, conquista da forma republicana e democrática de governo, decorrência do princípio da isonomia e do devido processo legal. Logo, a Administração Pública deve 
conceder tratamento igualitário a todos, vedados privilégios ou favorecimentos. Por certo que, quando se tratam de desiguais, é preciso tratá-los de maneira diferenciada a fim de igualá-los ou inseri-los perante os demais.

O referido artigo também menciona o direito a uma duração razoável do processo, ou a um tratamento tempestivo. Já é conhecida a afirmação de que a demora do atendimento de direitos nada mais é do que uma grande injustiça mascarada. A exigência de celeridade como fundamento de uma boa administração está ligada ao princípio da eficiência, mote da reforma gerencial brasileira introduzida pela Emenda Constitucional no 19/1998. Já em Portugal o direito ao atendimento das demandas num "prazo razoável" está previsto no artigo $52, \S 1$ da Constituição Portuguesa, bem como no artigo $58, \$ 1$, do Código de Procedimento Administrativo (prazo de 90 dias para conclusão de procedimentos administrativos).

$\mathrm{O}$ artigo $41 \$ 2$ fala do direito de audiência prévia do interessado antes de ser tomada qualquer medida individual que lhe desfavoreça. Nas palavras de Fabiana Carvalho Rocha,

O princípio audi alteram partem (ou audiatur altera pars = "ouvir a outra parte"), proveniente do Direito Romano, tem sido incorporado aos procedimentos administrativos dos países europeus. Baseia-se no pressuposto que não podem ser tomadas medidas contra um indivíduo antes dele ter tido uma oportunidade para se expressar. Em outras palavras, trata-se do direito de qualquer pessoa ser ouvida antes de a seu respeito ser tomada qualquer medida individual que a afete desfavoravelmente. $(2009,23)$.

Em Portugal o instituto da audiência pública está prevista no Código de Procedimento Administrativo, arts. 100 a 105, bem como o art. 117, na qual os interessados podem participar na formação das decisóes e atos administrativos. Nesse sentido é importante salientar o artigo 8 do mesmo diploma legal, que fala do princípio da participação, bem como os artigos 59 e 61 a 65 (direito de informação).

Por sua vez, o artigo $41 \$ 2$ da Carta de Direitos Fundamentais da União Europeia também prevê o direito a informação, ou seja, o direito a consultar e ter acesso a processos que lhe digam respeito. No mesmo sentido é o $\$ 4$, o qual garante às partes interessadas a possibilidade de se dirigirem às instituições ou órgãos europeus em uma das línguas oficiais dos tratados. Favorece-se, portanto, a que o interessado possa pleitear seus direitos perante os órgãos supranacionais na língua de origem, obtendo resposta na mesma língua, a fim de facilitar a comunicação e o exercício de seus direitos.

O problema do direito a informação foi muito debatido em conferência dos Provedores de Justiça Europeus. Nas conclusóes do encontro, entendeu-se que não basta apenas a informação, mas é preciso uma informação de qualidade, com linguagem clara e acessível. Para Eugen Muhr, Diretor da Provedoria da Áustria, é preciso dar uma formação adequada para os funcionários das repartições públicas, 
a fim de que forneçam informações completas, de maneira clara e inteligível ao cidadão comum, que deve ser orientado da melhor maneira possível. Ou seja, "A informação deve ser completa, global e os funcionários públicos devem mostrar toda a sua boa vontade para com o cidadão para que este não vá encontrar problemas." (1995, 115). No mesmo sentido o entendimento de Loukis Loucaides, Membro da Comissão Europeia dos Direitos do Homem,

um governo popular sem informação popular ou os meios de adquirir essas informações é o prólogo ou o prefácio de uma tragédia. [...] Uma sociedade em que o poder político é mandatado [sic] pelo povo, é necessário que o povo tenha informação sobre aquilo que se passa a nível público e que pode gerar debate e ter qualquer coisa a ver com as decisóes governamentais. Portanto, o acesso a documentos oficiais é parte dos direitos dos cidadãos para que recebam informaçôes, e uma das condiçôes para um país democrático e livre é justamente a do acesso a documentos públicos. (1995, 114).

No artigo $41 \S 3$ fala-se do direito a ser ressarcido quando lesado por atos e decisões dos órgãos e instituições supranacionais. Em Portugal essa matéria está prevista na Lei no 67/2007, que regula a Responsabilidade Civil do Estado e Entidades Públicas. Trata-se de matéria já bastante consolidada na doutrina nacional dos Estados-Membros da União Europeia, e advém da obrigatória responsabilidade que os órgãos e instituições públicas precisam ter quando cometerem atos ilícitos ou lícitos (desde que seja uma conduta anormal, exclusiva e que fira o princípio da isonomia) danosos a particulares.

Finalmente, fala-se, no artigo $41 \$ 1$, também do dever da Administração Pública motivar, fundamentar ${ }^{1}$ suas decisões. Esse dever também está consagrado em várias Constituições dos Estados-Membros, como a portuguesa, no artigo $268 \$ 3$, assim como o Código de Procedimento Administrativo português em seu artigo 124.

Ressalta-se que o dever de motivação está ligado ao direito de informação (Andrade 2003). Ou seja, é fundamental para que a parte possa ser informada plenamente sobre a decisão, a fim de saber o que levou o órgão a tomar aquele caminho, quais os motivos preponderantes do ato impugnado, com vistas inclusive a facilitar seu direito a defesa perante os Tribunais supranacionais.

1 Veja-se o entendimento de Vasco Pereira da Silva a respeito do assunto: "A fundamentação dos actos administrativos corresponde a uma exigência de transparência, típica de uma Administração dialógica, de um Estado de direito democrático, à qual não basta actuar bem, mas que deve igualmente ser capaz de explicar e de informar os particulares acerca das razōes da sua actuação. O dever de fundamentar é, assim, uma medida de 'higiene administrativa' que, para além do aspecto 'pedagógico', de obrigar a Administração a 'descer do seu pedestal' e explicar as razóes dos seus actos, possui ainda, por isso mesmo, o efeito indirecto de obrigar a uma maior correcção (jurídica e de mérito) das decisōes administrativas. Mas o dever de fundamentação é ainda importante do ponto de vista da protecção jurídica dos particulares, pois lhes permite averiguar da legalidade dos actos administrativos, o que é particularmente relevante quando se trate de decisões em que a Administração possua uma margem de livre apreciação ou de decisão, já que, nesses casos, muitas vezes essa é a única forma de controlar os fins e os motivos de dada actuação." (Silva 1999, 18). No mesmo sentido ver Silva (2009). 
Por meio da motivação podem-se evitar atos contrários à lei, ou irrazoáveis, contrários à moral ou ao interesse público. Facilita-se a atuação dos órgãos de controle, aproximando-se os mecanismos supranacionais de poder dos cidadãos europeus e obrigando-os a prestar contas de sua atuação.

Em conclusão, ao analisar o artigo 41, observa-se que a Carta de Direitos Fundamentais da Uniāo Europeia procurou ligar o termo "boa administração" aos princípios da moralidade, da eficiência, da motivação, da informação, da publicidade, da participação e da transparência. A partir do momento em que se torna jurídico o direito fundamental a uma boa administração, torna-se obrigatório que os organismos decisórios europeus passem a agir no sentido de dar concretude a esse direito. Para tanto, além de divulgar e informar, deverão motivar e justificar seus atos perante a cidadania europeia, bem como adotar uma rotina de prestação de contas com vistas a facilitar o controle formal e social do poder que lhes é conferido.

E para a fiscalização e controle do dever de bem administrar encontra-se um importante canal de comunicação entre cidadania europeia e instituições e órgãos comunitários: o Provedor de Justiça Europeu.

\section{Provedor de Justiça Europeu: atribuições e finalidades}

O Provedor de Justiça Europeu é uma instituição comunitária representada por um indivíduo nomeado pelo Parlamento Europeu com a função de, quer por iniciativa própria quer baseado em queixas que lhe tenham sido apresentadas por cidadãos e residentes europeus, investigar e proceder a inquéritos sobre irregularidades na atuação dos órgãos comunitários, bem como emitir recomendaçôes com o fim de corrigir os casos de má administração e violação aos direitos humanos por ele detectados.

A instituição do Provedor de Justiça Europeu está regulamentada na Carta dos Direitos Fundamentais da União Europeia, em seu artigo 43, bem como no Tratado que institui a União Europeia, artigos 21 e 195 e, por fim, no Estatuto do Provedor de Justiça Europeu, aprovado em 9 de maio de 1994. (Estatuto do Provedor de Justiça Europeu 2012). Não dispõe de um catálogo preciso de direitos a defender. Logo, age com total independência e imparcialidade no cumprimento de suas funçôes. Veja-se o artigo 43 da Carta dos Direitos Fundamentais da União Europeia (2012), o qual dispõe que

Qualquer cidadão da União, bem como qualquer pessoa singular ou coletiva com residência ou sede social num Estado-Membro, tem o direito de apresentar petiçōes ao Provedor de Justiça da União, respeitantes a casos de má administração na atuação das instituições ou órgãos comunitários, com exceção do Tribunal de Justiça e do Tribunal de Primeira Instância no exercício das respectivas funçôes jurisdicionais. 
O artigo em questão abre a possibilidade de que não apenas cidadãos europeus, mas também qualquer pessoa singular ou coletiva com residência ou sede estatutária num Estado-Membro, dirija petiçōes ao Provedor de Justiça Europeu. As queixas podem vir diretamente ou por meio de um deputado ao Parlamento Europeu.

O objeto de atuação do Provedor de Justiça Europeu é o exercício da atividade política e a prestação dos serviços públicos, em âmbito comunitário. Trata-se um canal de acesso da cidadania aos órgãos de poder político, controlando a má atuação das instituições ou organismos comunitários e a violação de direitos. Órgão que atua perante todos os cidadãos europeus de forma gratuita, unipessoal, apolítico e independente, cujas investigações são públicas, eleito pelo Parlamento Europeu com amplos poderes de supervisão no intuito maior que é a persecução do direito fundamental a uma boa administração.

O primeiro Provedor de Justiça Europeu foi o finlandês Jacob Södermann, eleito em 12 de julho de 1995 pelo Parlamento Europeu. Deve ser cidadão da União, em pleno gozo dos direitos civis e políticos, com exclusividade de atuação. É nomeado pelo Parlamento Europeu após cada eleição deste, e pela duração da legislatura do Parlamento. Tem a possibilidade de demissão pelo Tribunal de Justiça mediante solicitação do Parlamento Europeu, quando não preencher os requisitos necessários para o desenvolvimento de sua função ou no cometimento de falta grave (Ribeiro 2002, 1242-1261).

A instituição do Provedor de Justiça originou-se dos países nórdicos, e sempre esteve fortemente ligada a noções de democracia, controle social e transparência do exercício do poder político. Já estava presente, em 1809, na Constituição da Suécia, com a denominação ombudsman, figura recepcionada posteriormente na Finlândia e Dinamarca e, logo após, expandida para muitos outros países nos mais diversos continentes, como Portugal, Espanha, Estados Unidos, Inglaterra, Nova Zelândia e Austrália, dentre outros. Entretanto, é a Europa o continente onde existe o maior número de Provedorias do mundo, havendo aproximadamente 40 , tanto em âmbito nacional quanto regional ou local, em diversos países. Nas palavras de António Sequeira Ribeiro, "o ombudsman só tem razão de existir em sociedades democráticas, cujo regime permita o controle da legalidade dos actos da administração e a defesa dos direitos fundamentais dos cidadãos." (2002, p. 1241).

Tem o poder de requerer perante as autoridades nacionais, desde que não sigilosas, todas as informaçôes que possam contribuir para o desvelamento dos casos de má administração nas instituições comunitárias: a Comissão Europeia, o Conselho da União Europeia e o Parlamento Europeu. Da mesma forma, também atua perante reclamações dos órgãos comunitários como, por exemplo, a Agência Europeia de Avaliação de Medicamentos e a Fundação Europeia para a Melhoria de Condições de Vida e de Trabalho. Atua como órgão de controle formal em casos de violação da lei, má administração ou violação dos direitos humanos. Excluem-se de sua atuação as funções comunitárias jurisdicionais. 
Para vencer a tentação com as características atrás referidas e evitar assim que o PJE se transforme num ilustre inspector de serviços há que interpretar extensivamente o conceito de má administração tendo em conta os efeitos da valoração de tal conceito, o que nos leva às omissões, aos actos discricionários, às normais relações de sujeição especial com determinados agentes, etc. [...], e igualmente interpretar extensivamente os parâmetros de referência em que o Provedor se pode apoiar na hora de defender direitos dos cidadãos frente a casos de má administração. Direitos dos cidadãos que não se restringem aos direitos económicos mas que se estendem aos novos direitos dos cidadãos, às políticas comunitárias, aos fins da União, e à defesa dos direitos dos cidadãos de acordo com o estabelecido pela Convenção Europeia dos Direitos do Homem. (Ribeiro 2002, 1253).

Logo, na persecução do direito fundamental dos cidadãos europeus a uma boa administração, o Provedor de Justiça tem uma tarefa que é dupla: atuar como mecanismo de controle externo dos órgãos e das instituiçôes comunitárias, investigando queixas dos cidadãos europeus sobre má administração e recomendando ações corretivas, quando necessário. E, de outra banda, tem a intenção de colaborar com o incremento das atividades por elas executadas, auxiliando-as a incrementar seu desempenho e, em consequência, melhorar os serviços públicos prestados aos cidadãos europeus. É, portanto, um canal de ligação entre os cidadãos e os órgãos e instituições de poder supranacionais.

Para delimitar o alcance das atividades do Provedor de Justiça Europeu, bem como firmar entendimento do que seria uma "boa administração pública", foi editado pela Provedoria de Justiça e aprovado pelo Parlamento Europeu, em 6 de setembro de 2001, uma Resolução sobre um Código Europeu de Boa Conduta Administrativa. Por certo o termo "boa administração" é mais um exemplo de conceito jurídico indeterminado. Porém, tem-se no Código um importante caminho para sua identificação. Trata-se, portanto, de

uma ferramenta vital que o Provedor de Justiça tem à sua disposição para prosseguir o seu objectivo e usa-a para examinar se está perante um caso de má administração, apoiando-se nas suas normas para essa função de controle. O Código serve igualmente de guia e é um recurso útil aos funcionários públicos europeus, encorajando um padrão mais exigente para a Administração. (Código Europeu de Boa Conduta Administrativa 2012).

Acaso a queixa dirigida ao Provedor não se trate de assunto de sua competência como, por exemplo, se tratar de um ato de uma autoridade nacional ou regional dos Estados-Membros, o Provedor de Justiça Europeu poderá encaminhá-la aos membros da Rede Europeia de Provedores de Justiça. Essa rede foi criada em 1996, e "engloba todos os Provedores nacionais e regionais dos Estados-Membros, dos 
países candidatos e da Noruega e Islândia e ainda todas as comissões das petições existentes na UE." (Provedor de Justiça Europeu 2012).

Quando o assunto for de sua competência, o Provedor de Justiça Europeu procederá com os inquéritos necessários e apresentará o assunto à instituição em causa, para defesa ou correção imediata do problema. Acaso não obtenha êxito, tentará uma solução amigável entre as partes, podendo ainda fazer recomendaçôes com vistas a resolver o caso. Se mesmo assim não houver solução, ele elaborará um relatório especial encaminhando ao Parlamento Europeu para providências. Ao final do procedimento, o Provedor enviará um relatório conclusivo ao Parlamento Europeu, à instituição acusada e à pessoa que apresentou a queixa. Também é seu dever apresentar ao Parlamento Europeu um relatório anual sobre os resultados de seus inquéritos, desde que não viole ao dever de sigilo que é inerente à função.

Conforme o Relatório Anual de 2000, publicado pelo gabinete da Provedoria de Justiça Europeia na presidência de Jacob Söderman, no decorrer dos anos está havendo um incremento na atividade do Provedor. Foram 1.577 queixas recebidas em 1999, para 1.732 queixas em 2000. Apesar de registros de queixas em quase todos os países europeus, nota-se uma preponderância nos registros de França, Alemanha e Espanha. Do total das reclamações, no ano de 1999 foram convertidas 201 queixas em inquéritos, aumentando para 223 em 2000. Por sua vez, em 2000 foram encerrados 237 inquéritos com decisões fundamentadas, enquanto em 1999 foram 203. Das queixas encerradas no ano de 2000, encontram-se os seguintes fundamentos: em 112 casos não foi detectada má administração; em 76 casos houve um desfecho favorável ao queixoso; em 31 queixas foram feitas observaçóes críticas; em 1 caso foi encontrada uma solução amigável; em 12 casos os projetos de recomendação formuladas pelo Provedor foram aceitas pela instituição comunitária em causa; e, por fim, 2 queixas deram azo à elaboração de um relatório especial. (Provedor de Justiça Europeu 1995).

Dessa forma, o Provedor de Justiça Europeu é uma instituição apta a privilegiar a participação dos cidadãos no controle de seus representantes políticos, diminuindo assim o distanciamento e o deficit democrático que tantos autores criticam nas instituições comunitárias europeias. Porém, conforme as conclusões de António Sequeira Ribeiro, é uma instituição que precisa ainda ser aprimorada. Veja-se:

Pensado como um instrumento para a defesa dos cidadãos e de controle do poder, pode no entanto acabar como um elemento perturbador no conjunto de todos os controles, ou sem chegar a sê-lo pode converter-se num adorno que redunde em ineficácia num panorama suficientemente carregado de incertezas, reservas e cepticismos, quando o momento exigia mais uma resposta de betão do que uma intervenção cosmética. [...] A partir de uma dada altura pensou-se na criação de uma figura em todo idêntica àquela que nos diversos Estados-Membros corresponde ao Ombudsman. Só que não basta o nome nem o simples acto de criação. É necessário regular e dar poderes ao órgão criado sob pena de se criar uma ficção. Com a instituição da cidadania europeia pelo 
TUE pensou-se em criar meios de natureza graciosa e contenciosa para defesa dos mesmos. A partir de dada altura já não havia, quanto a nós, força política para fazer marcha atrás. Daqui nasce no artigo 138.-E o PJE, mas nasce com um objectivo um pouco ambíguo, pouco definido, expresso na expressão má administração. O Estatuto de quem muito se esperava com vista à clarificação da matéria, não trouxe em termos de substrato nada de novo, limitando-se isso sim a regular aspectos puramente organizatórios que melhor seria que tivessem sido regulados noutra sede. Criou-se a figura mas depois teve-se receio de ir mais além ou pelo menos de a fazer assentar naqueles pilares que são tidos como essenciais a qualquer Provedor. [...]" (2002, p. 1245).

Além disso, o autor salienta a necessidade de o Provedor poder escolher seus colaboradores diretos, os quais deveriam ser pessoas capazes de desempenhar funções de caráter jurídico, com experiência profissional de grande qualidade. Da mesma forma devem ser resolvidas as questões orçamentárias, já que sem dinheiro é muito difícil uma atuação satisfatória. Também importa registrar a crítica de Marcelo Rebelo de Sousa, para o qual a instituição do Provedor de Justiça Europeu, até agora,

tem ficado muito aquém das expectativas criadas, não só porque os cidadãos não lhe têm acesso por falta de meios, nomeadamente por falta de conhecimento da sua actuação, mas também por falta de importância, a qual lhe tem sido negada pelos mais relevantes órgãos comunitários, a começar pelo Parlamento Europeu. Este fez um esforço inicial para o valorizar, mas na prática não lhe tem dado qualquer relevo. (Sousa 1997, 126).

Para Marcelo Rebelo de Sousa, é preciso alargar as competências do Provedor Europeu, a fim de que possa se reportar também aos órgãos jurisdicionais europeus, como o Tribunal de Justiça. Alargar, portanto, o seu regime de atuação, com vistas a defender os direitos dos cidadãos europeus da mesma forma que alguns dos Provedores de Justiça nacionais como, por exemplo, em Portugal, em que a instituição está apta a atuar em questões de inconstitucionalidade, suscitando a intervenção do Tribunal Constitucional. $\mathrm{O}$ autor salienta que em Portugal o Provedor de Justiça tem legitimidade também para suscitar a nulidade de cláusulas contratuais gerais, presentes em contratos de adesão, contrárias à lei, atitude que se exerce por determinação da lei "entre" e "contra” entidades privadas. Porém, em âmbito europeu isso não é possível. João Gonçalves, Coordenador da Provedoria de Justiça de Portugal, assim argumenta ao defender a equiparação das atividades do Provedor de Justiça europeu ao português:

Nestes termos se integra a possibilidade, inexistente mas que se defende, de suscitar junto aos órgãos competentes a anulação de actos administrativos, a declaração de ilegalidade de regulamentos e, como última racio já hoje assegurados ao Provedor de Justiça pela constituição Portuguesa, o pedido de 
declaração de inconstitucionalidade de normas jurídicas com força obrigatória geral. Mais do que nunca, face à impenetrabilidade mútua da Administração e dos administrados, justifica-se a existência de uma entidade que carreie os anseios e protestos de uma parte, sem deixar de justificar, explicando devidamente o seu porquê, as decisóes tomadas quando entenda que em rigor o deve fazer. Como tudo o que é humano, o Ombudsman deve evoluir com a sociedade em que se integra. Até agora a instituição, nas suas diversas 'encarnações históricas', tem-se adaptado às novas exigências, mas é necessário e imperioso que, numa perspectiva activa, saiba construir os caminhos do futuro. A democracia e o Direito assim o exigem. (Gonçalves 1995, 121).

Já William Reid, Provedor de Justiça do Reino Unido, entende que é preciso simplificar os mecanismos de apresentaçōes das queixas perante o Provedor de Justiça, o qual deve investigar imparcialmente todos os aspectos da questão, verificando se é pertinente ou não. Deve assegurar que a má administração não seja repetida, bem como que ela seja reparada, visto que por vezes esses assuntos têm consequências de caráter financeiro. Da mesma forma, é importante que haja guias deontológicos para a prática de serviços públicos (existentes na GrãBretanha), capazes de orientar a atuação não só dos servidores, mas do ombudsman e, principalmente, dos cidadãos, que passam a estar mais informados sobre como utilizar melhor os serviços públicos, bem como seus direitos. Deve o ombudsman ter um papel mais construtivo e positivo, em vez de ser meramente crítico, já que a experiência no recebimento de queixas e no processo investigatório lhe dá uma boa visão da operacionalidade dos órgãos e instituições supranacionais. Por ter mobilidade entre sociedade civil e sociedade política, poderá identificar os problemas e detectar quais os procedimentos que devem ser alterados. (1995, 104-107).

Dessa forma, o presente artigo defende o aprofundamento da instituição do Provedor de Justiça como fundamental para o processo de constitucionalização dos direitos fundamentais e na legitimação dos órgãos comunitários perante a cidadania europeia. Nas palavras de António Sequeira Ribeiro, "na medida que o ombudsman parece ter entrado nos cânones do constitucionalismo contemporâneo, o seu acolhimento a nível comunitário pode considerar-se como um passo simbólico no caminho da constitucionalização da União Europeia" (2002, p. 1245). Visa, portanto, a aproximar os órgãos comunitários dos cidadãos, tornando mais transparentes os complexos mecanismos de decisão supranacionais, aumentando assim o grau de legitimação dos órgãos comunitários perante a cidadania que os pressupõe.

\section{Considerações finais}

O que se discutiu no presente artigo foram os avanços e retrocessos no processo de constitucionalização da União Europeia e a sua relação com a cidadania europeia e os direitos fundamentais. 
Os Estados-Membros da União Europeia seguem sendo os mesmos Estados nacionais, porém já não têm as mesmas competências que definiam o poder estatal no século 19. A moeda, por exemplo, foi substituída pelo euro, perdendo cada Estado o poder político de regular a própria moeda em seu território. Também não há fronteiras interiores capazes de permitir aos Estados-Membros estabelecerem seu próprio direito. E há também uma cidadania europeia que tem direito a voto em eleições ao Parlamento Europeu, bem como eleições municipais, mesmo residindo em outros Estados que não da sua origem. Em parte pertencem ao Estado, em parte pertencem à União Europeia.

Logo, a estatalidade já não é uma característica fechada em si mesma, mas agora admite uma gradação. Os Estados-Membros da União Europeia perderam estatalidade, por um lado, mas ganharam, por outra. A União Europeia não é um Estado enquanto organização política internacional, porém tem qualidade estatal, com traços distintivos próprios, diferentes dos Estados-nação clássicos. Logo, é falso afirmar que não é possível construir um Estado na Europa, pois este Estado já existe, em alguma medida.

O que se discute neste artigo é, mediante tantas transformaçôes, o lugar que estará a cidadania europeia e, em decorrência, os direitos fundamentais dos seus cidadãos, bem como a necessidade de aprimorar os mecanismos de controle social do poder, agora supranacional.

Há uma transformação, em que não se pode mais aplicar no processo de integração europeia modelos antigos. É preciso criar novas categorias, porque se está frente a uma nova realidade. E é necessário compreendê-la para, a partir daí, elaborar essas novas categorias. Alguns afirmam que a Europa está em parte estagnada, e precisa encontrar formas criativas de avançar. Para Peter Sloterdik, está em voga a forma de transição neste novo milênio da modernidade, capaz de se chegar a "uma nova criação de forma política, para lá do Império - acima do Império, acima dos Estados-nação -, e então uma coisa se torna clara: a política do futuro depende em larga medida de uma modernização da função visionária ou profética da inteligência.” (Sloterdik 2008, 51).

E para isso é preciso aumentar o poder político, o âmbito de competência da União Europeia, bem como encontrar novas formas de participação cidadã e accountability com vistas a superar o deficit democrático dos órgãos comunitários. Essa é a única saída para os Estados europeus manterem seu sistema de vida e sua cultura constitucional e política, com a garantia dos direitos fundamentais, em especial dos direitos sociais. Tenciona manter o espaço europeu como um espaço democrático e privilegiado no reconhecimento dos direitos fundamentais.

Por sua vez, é imprescindível o aprimoramento da atuação do Provedor de Justiça Europeu na interface entre sociedade política e sociedade civil, bem como a criação de novas formas de participação do cidadão nas instituições comunitárias, sob pena de estar-se desenvolvendo uma União apenas para os Estados-Membros, e não para os cidadãos, razão de ser do próprio Estado. 
A fortaleza da União Europeia, em verdade, é a existência de uma jurisdição conjunta. E para tanto já há o tribunal constitucional europeu. Cada vez mais o precedente jurisdicional nas Cortes Europeias passa a tomar maior força, chegandose a afirmar que "o direito europeu é o que o tribunal europeu diz que é". Dessa forma, imprescindível se mostra a possibilidade de o Provedor de Justiça Europeu poder atuar também perante os órgãos jurisdicionais supranacionais, com vistas a defender os direitos fundamentais dos cidadãos europeus. Porém, isso ainda é um processo. Cada organização política deve buscar uma solução para seus problemas constitucionais, a partir de sua realidade.

Entende-se que a partir da jurisdição europeia, via Carta de Direitos Fundamentais e atuação do Provedor de Justiça Europeu, se dará a confluência entre os ordenamentos jurídicos tendo como centralidade não mais os Estados, mas sim a cidadania europeia. Será também possível controlar, via jurisdição, os poderes das instituiçôes supranacionais e novos órgãos de poder. E nesse sentido, a esfera pública europeia, a que tanto defende Habermas, virá a partir da atuação do tribunal europeu, inserindo os cidadãos pela via da efetivação dos direitos fundamentais.

Logo, a democratização da União Europeia reclama instituições políticas capazes de representar e/ou intermediar interesses entre instituições europeias e sociedade civil, canais de ligação entre a representação e a cidadania, a fim de proporcionar uma relação dialógica entre os atores envolvidos e decisões mais afinadas com o interesse público. E a Figura do Provedor de Justiça Europeu se mostra uma importante instituição na busca desse objetivo.

Sabe-se que o desafio de consolidação da democracia e o seu aprendizado é um caminho árduo e tortuoso, a ser conquistado dia após dia. No dizer de Claude Leford, seguido por Marilena Chauí, democracia é uma constante invenção, a ser inventada no cotidiano, criando-se novos direitos e reafirmando-se os já estabelecidos, reinstituindo-se o social e o político. Tem um caráter aberto e subversivo, questionando suas instituições e se recriando a todo o momento. (1997, 209).

O reconhecimento da juridicidade da Carta de Direitos Fundamentais e, da mesma forma, a instituição do Provedor de Justiça como defensor do direito fundamental a uma boa administração foram importantes passos na democratização da União Europeia e no desenvolvimento de uma cidadania comunitária. Mas é preciso avançar. E para concretizar mais efetivamente o direito a uma boa administração, fundamental incrementar-se mecanismos de controle social e de participação dos cidadãos nas instâncias supranacionais de poder.

\section{Referências bibliográficas}

ANDRADE, José Carlos Vieira de, (2003) O Dever da Fundamentação de Actos Administrativos. Coimbra: Almedina. 
CALlEJÓN, Francisco Balaguer (Coord.) (2010) Manual de Derecho Constitucional. v. I. 5. ed. Madrid: Tecnos.

CALLEJÓN, Francisco Balaguer (2012). La Constitución Europea trás El Consejo Europeo de Bruxelas y El Tratado de Lisboa. Revista de Derecho Constitucional Europeo n. 8, jul./dez. 2007. Disponível em <http://www.ugr.es/ redce/>, acessado em 31 maio 2012.

CALLEJÓN, Francisco Balaguer. Los Tribunales Constitucionales en el Processo de Integración Europea. Revista de Derecho Constitucional Europeo n. 7. jan./jun. 2007. Disponível em $<$ http://www.ugr.es/ - redce/>, acessado em 31 maio 2012.

CARTA DE DIREITOS FUNDAMENTAIS DA UNIÃO EUROPEIA (2012). Disponível em <http://www.europarl.europa.eu/charter/pdf/text_pt.pdf>, acessado em 31 maio 2012.

CÓDIGO EUROPEU DE BOA CONDUTA ADMINISTRATIVA (2012). Disponível em $<$ http://www.ombudsman.europa.eu/pt/resources/code.faces>, acessado em 31 maio 2012.

ESTATUTO DO PROVEDOR DE JUSTIÇA EUROPEU (2012). Disponível em <http://www.ombudsman.europa.eu/pt/resources/statute.faces>, acessado em 31 maio 2012.

GARCÍA DE ENTERRÍA, Eduardo (2000) Curso de Derecho Administrativo. V. 1. Madrid: Civitas. GONÇALVES, João (1995) A Proteção dos Cidadãos enquanto "Consumidores" dos Serviços Governamentais-Debates. In: PROVEDORIA DE JUSTIÇA. 4. Mesa Redonda dos Provedores de Justiça Europeus. Lisboa: Assembleia da República.

GRIMM, Dieter (2006) Constituição e Política. Tradução de Geraldo de Carvalho. Belo Horizonte: Del Rey.

HÄBERLE, Peter. ¿Tienen España y Europa una Constitución? (2012) Traducido del alemán por Miguel Azpitarte Sánchez. Revista de Derecho Constitucional Europeo n. 12, jul./dez. 2009, p. 353-393. Disponível em <http://www.ugr.es/-redce/>, acessado em 31 maio 2012.

HABERMAS, Jürgen (2012) Por qué Europa necesita uma Constitución. Revista Bimestral de Pensamiento Social. La Factoría. n. 25-26, Colomers, oct./abr. 2005. Disponível em <http:// www.revistalafactoria.eu/imprimir.php?tipo=articulo\&id=274>, acessado em 31 maio 2012.

HAURIOU, Maurice (1938) Précis Elementaire de Droit Administratif. 4.ed. Recueil Sirey.

I. PERNICE (2012) Multilevel Constitutionalism and the Treaty of Amsterdam: European Constitution-Making revisited? Common Market Law Review, n. 36, 1999. Disponível em <http://www.whi-berlin.de/documents/whi-paper0499.pdf>, acessado em 31 maio 2012.

CHAUÍ, Marilena (1997) Cultura e democracia. 7. ed. São Paulo: Cortez.

LEÓN, Baldomero Oliver (2012) El Derecho de Sufragio como Elemento Estructural de la Ciudadania Europea. Revista de Derecho Constitucional Europeo n. 4, jul./dez. 2005, p. 197-218. Disponível em <http://www.ugr.es/ redce/>, acessado em 31 maio 2012.

LOUCAIDES, Loukis (1995) A Proteção dos Cidadãos enquanto "Consumidores" dos Serviços Governamentais-Debates. In: PROVEDORIA DE JUSTIÇA. 4. Mesa Redonda dos Provedores de Justiça Europeus. Lisboa: Assembleia da República.

MONETTE, Pierre-Yves (2008) A Boa Governação ao Serviço do Desenvolvimento Duradouro. In: RODRIGUES, Nascimento H. O Provedor de Justiça: novos estudos. Lisboa: Provedoria de Justiça. 
MUHR, Eugen (1995) A Proteção dos Cidadãos enquanto "Consumidores" dos Serviços Governamentais-Debates. In: PROVEDORIA DE JUSTIÇA. 4. Mesa Redonda dos Provedores de Justiça Europeus. Lisboa: Assembleia da República.

OSÓRIO, Fábio Medina (2007) Teoria da Improbidade Administrativa. São Paulo: Revista dos Tribunais.

PRINCÍPIOS GERAIS DA BOA ADMINISTRAÇÃO (2012). Disponível em <http:// ec.europa.eu/civil_society/code/general_pt.htm>, acessado em 31 maio 2012.

PROVEDOR DE JUSTIÇA EUROPEU (2012). Disponível em <http://www.ombudsman. europa.eu/pt/atyourservice/ataglance.faces $>$, acessado em 31 maio 2012.

PROVEDOR DE JUSTIÇA EUROPEU (1995). Relatório Anual 2000. Estrasburgo: Serviços do Parlamento

PROVEDORIA DE JUSTIÇA. 4. Mesa Redonda dos Provedores de Justiça Europeus. Lisboa: Assembleia da República.

REID, William (1995) A Protecção dos Cidadãos enquanto 'Consumidores' dos Serviços Governamentais-Debate. In: PROVEDORIA DE JUSTIÇA. 4. Mesa Redonda dos Provedores de Justiça Europeus. Lisboa: Assembleia da República.

RIBEIRO, António Sequeira (2002) Do Provedor de Justiça Europeu: algumas considerações. Separata de AB VNO AD OMNES: 75 anos da Coimbra Editora. Coimbra: Coimbra Editora.

ROCHA, Fabiana Carvalho (2009) O Instituto Jurídico da Boa Administração. Relatório Final da Disciplina Direito Administrativo. Mestrado em Ciências Jurídico-Políticas. Orientador: Vasco Pereira da Silva. Faculdade de Direito da Universidade de Lisboa, Lisboa.

SILVA, Vasco Pereira da (1999) O Contencioso Administrativo como "Direito Constitucional Concretizado" ou "Ainda por Concretizar"? Coimbra: Almedina.

SILVA, Vasco Pereira da (2009) O Contencioso Administrativo no Divã da Psicanálise: ensaio sobre as acçôes no novo processo administrativo. 2. ed. Coimbra: Almedina.

SLOTERDIK, Peter (2008) Se a Europa Acordar. Reflexões sobre o programa duma potência mundial no termo de sua ausência política. Trad. de Manuel Resende. Lisboa: Relógio d'Água.

SOUSA, Marcelo Rebelo de (1997) A Cidadania Europeia - Nível de Concretização dos Direitos, Possibilidade de Alargamento e suas Implicaçōes. In: PEREIRA, André Gonçalves et al. Em Torno da Revisão do Tratado da União Europeia. Coimbra: Almedina.

Recebido em 1ํㅡㄹ junho de 2012

Aprovado em 18 de julho de 2012

\section{Resumo}

O artigo visa a analisar as questões da cidadania europeia e do deficit democrático das instituições supranacionais. Nesse sentido, aborda a instituição do Provedor de Justiça Europeu. Trata-se de um indivíduo nomeado pelo Parlamento Europeu com a função de, quer por iniciativa própria 
quer baseado em queixas que lhe tenham sido apresentadas por cidadãos e residentes europeus, investigar e proceder a inquéritos sobre irregularidades na atuação dos órgãos comunitários, bem como emitir recomendações com o fim de corrigir os casos de má administração e violação aos direitos humanos por ele detectados. O objeto de atuação do Provedor de Justiça Europeu é o exercício da atividade política e a prestação dos serviços públicos, em âmbito comunitário. Trata-se um canal de acesso da cidadania aos órgãos de poder político, controlando a má atuação das instituições ou organismos comunitários e a violação de direitos, com amplos poderes de supervisão no intuito maior que é a persecução do direito fundamental a uma boa administração.

Palavras-chave: boa administração; cidadania; provedor de justiça.

\begin{abstract}
This paper aims to analyze the questions on the European citizenship and the democratic debt of the supranational institutions. In this sense it addresses the institution of the European Provider of Justice. It is about an individual appointed by the European Parliament with the task of, either by its own initiative or based on complaints presented by European citizens and inhabitants, investigating and proceeding to investigation about irregularities on the actuation of the communitarian organs, as well as to emit recommendations with the aim of correcting the cases of bad administration and violation of the human rights detected by it. The object of actuation of the European Provider of Justice is the enforcement of political activity and the providing of public services in a communitarian set. It is an access channel for the citizenship to the organs of political power, controlling the bad actuation of the institutions or communitarian organisms and the violation of rights, with broad powers of supervision with the aim of the enforcement of the fundamental right to a good administration.
\end{abstract}

Keywords: good administration; citizenship; ombudsman. 